\title{
PREOPERATIVE RISK MODELS FOR MINIMALLY INVASIVE CORONARY BYPASS: A PRELIMINARY STUDY
}

Marco Zenati, MD

Howard A. Cohen, MD

Richard Holubkov, PhD

A. J. Conrad Smith, MD

Arthur J. Boujoukos, MD

John Caldwell, MD

Leonard Firestone, MD

Bartley P. Griffith, MD
Objective: Available risk assessment models are designed for standard coronary artery bypass grafting. We hypothesized that minimally invasive coronary bypass could improve on predicted outcome in extremely high-risk patients (Parsonnet score $>\mathbf{2 0 \%}$ ) by the current risk models. Methods: From September 1996 to September 1997, 27 consecutive extremely high-risk patients underwent minimally invasive coronary bypass. Seventeen patients were male; age was $73 \pm 12$ years, and $63 \%$ of patients were older than $\mathbf{7 5}$ years. Left ventricular ejection fraction was $33.7 \% \pm 15 \%$ and $63 \%$ had an ejection fraction of less than $35 \%$. The predicted 30-day mortality according to the System 97 model was $25.6 \% \pm 11.3 \%$. The Parsonnet risk score was $36.2 \% \pm 11 \%$; the predicted length of stay in the hospital was $15.3 \pm 3$ days. The predicted risk of stroke according to the Multicenter Perioperative Stroke Risk Index was $22.3 \% \pm 11.7 \%$. Results: Minimally invasive coronary bypass was isolated in 20 patients and integrated with angioplasty and stenting in 7 patients. The observed 30-day mortality was $0 \%$ ( $P<.01$ vs predicted): at an average follow-up of $10.8 \pm 4.1$ months, 26 patients $(96.3 \%)$ are alive without angina; one patient with acquired immunodeficiency syndrome died on postoperative day 40 of acute pancreatitis. No patient had a stroke or neurologic deficit $(P<.01$ vs predicted). Patency of internal thoracic artery anastomosis was confirmed by angiography in all 27 patients. No patient required reoperation. Eighteen patients $(67 \%)$ were extubated in the operating room. The observed length of hospital stay after minimally invasive coronary bypass was $3.8 \pm 2.6$ days $(P<.01$ vs predicted). Conclusion: On the basis of our results on a relatively small series of patients, we suggest that risk models geared for standard coronary bypass grafting may not be appropriate for minimally invasive coronary bypass. (J Thorac Cardiovasc Surg 1998;116:584-9)
T he success and aggressive application of percutaneous coronary revascularization techniques ${ }^{1}$ has contributed at least in part to the increase of the mean age and risk profile for patients referred for coronary artery bypass grafting $(\mathrm{CABG}) .^{2}$ Despite refinement of

From the Divisions of Cardiothoracic Surgery, Cardiology, Critical Care Medicine, and Anesthesiology, University of Pittsburgh Medical Center, Pittsburgh, Pa.

Presented in part at the Seventieth Scientific Sessions of the American Heart Association, Orlando, Fla, Nov 9-12, 1997.

Received for publication March 3, 1998; revisions requested May 26, 1998; revisions received June 23, 1998; accepted for publication June 24, 1998.

Address for reprints: Marco Zenati, MD, Division of Cardiothoracic Surgery, University of Pittsburgh Medical Center, 200 Lothrop St, Suite C-700, Pittsburgh PA 15213-2582.

Copyright $\odot 1998$ by Mosby, Inc.

0022-5223/98 $\$ 5.00+0 \quad \mathbf{1 2 / 1 / 9 2 8 0 7}$ surgical and anesthesiology techniques, patients with significant preoperative risk factors are at increased risk of dying or having complications after CABG. The major cause of complications during $\mathrm{CABG}$ is related to the use of cardiopulmonary bypass (CPB) and cardioplegia, ${ }^{3}$ which in turn may lead to perioperative myocardial infarction in $5 \%$ to $10 \%$ of patients. Furthermore, hemodilution, reduced mean perfusion pressure to the brain during $\mathrm{CPB},{ }^{4}$ cannulation, and clamping and manipulation of the aorta required for construction of proximal anastomoses expose patients to the risk of stroke. ${ }^{5}$

Minimally invasive CABG (MICABG) through a minithoracotomy without CPB recently has been introduced successfully into clinical practice. ${ }^{6} \mathrm{We}^{7}$ and others $^{8}$ have demonstrated decreased resource use and improved results of MICABG compared with standard CABG. On the basis of these results, we hypothesized 
Table I. Baseline clinical characteristics in 27 patients

\begin{tabular}{ll}
\hline Age $(\mathrm{y})$ & $73 \pm 12$ \\
Age $>75$ y (\%) & 63 \\
Sex (\%) & \\
Female & 37 \\
Male & 63 \\
LVEF (\%) & $33.7 \pm 15$ \\
Unstable angina (\%) & 85 \\
Prior CABG (\%) & 7.4 \\
No. of diseased vessels & \\
One (\%) & 4 \\
Two (\%) & 33 \\
Three (\%) & 33 \\
Left main (\%) & 30 \\
\hline
\end{tabular}

LVEF, Left ventricular ejection fraction; $\mathrm{CABG}$, coronary artery bypass graft.

that MICABG, perhaps by avoiding $\mathrm{CPB}$, could improve results in patients in whom CABG is a high-risk procedure. Inasmuch as the available risk assessment models are designed for standard CABG, we also hypothesized that these models would not be able to accurately predict the outcome when MICABG was performed instead of the standard CABG.

\section{Methods}

Patient population. From September 1996 to September 1997, 108 MICABG procedures were performed at the University of Pittsburgh MeGoiter 1dical Center by 2 surgeons (M.Z. and B.P.G.). Among these 108 patients, 27 (25\%) had a Parsonnet risk score ${ }^{9}$ greater than $20 \%$ : these consecutive 27 "extremely high-risk" 10 patients are the focus of the present observational study.

Patient demographics are listed in Table I and risk factors present in these patients (not mutually exclusive) are listed in Table II. Twenty patients $(20 / 27,74 \%)$ had been turned down as candidates for standard CABG by 1 or more surgeons because of anticipated prohibitive risk. The remaining 7 patients were never referred for conventional CABG by the cardiologist and would have been deemed to be candidates for medical therapy if MICABG were not available. All patients were in Canadian Cardiovascular Society angina class III or greater or had objective evidence of ischemia.

Risk assessment models and definitions. The risks that were assessed were (1) 30-day mortality; (2) perioperative stroke; and (3) prolonged hospital stay after the procedure.

The risk of dying (30-day mortality) after CABG was calculated with the use of the "System 97"11: this model, unlike other models currently used, has been shown to approximate the observed mortality after CABG extremely well and recently has been extensively validated (Bernstein AD, personal communication, December 10, 1997).

The risk of prolonged hospital stay after CABG was calculated by means of a regression equation based on the Parsonnet score. ${ }^{2}$ The correlation coefficient between observed length of stay after CABG and the Parsonnet score is
Table II. Risk factors (not mutually exclusive)

\begin{tabular}{lc}
\hline Risk factor & Percent of patients \\
\hline CHF & 67 \\
Severe PVD & 63 \\
Severe COPD & 70 \\
Renal dysfunction & 55 \\
Age $>75$ y & 63 \\
LVEF < 35(\%) & 63 \\
Previous CVA & 74 \\
\hline
\end{tabular}

$C H F$, Congestive heart failure; $P V D$, peripheral vascular disease; $C O P D$, chronic obstructive pulmonary disease; $L V E F$, left ventricular ejection fraction; $C V A$, cerebrovascular accident.

Table III. Predicted versus observed risks

\begin{tabular}{llcc}
\hline & Predicted & Observed & P value \\
\hline Mortality (\%) & $25.6 \pm 11.3$ & 0 & $<.001$ \\
Stroke (\%) & $22.3 \pm 11.7$ & 0 & $<.001$ \\
LOS (d) & $15.3 \pm 3$ & $3.9 \pm 3.5$ & $<.001$ \\
\hline
\end{tabular}

$L O S$, Length of hospital stay.

very high $(r=0.976)$. Length of hospital stay is also a good predictor of complication rate and of resource use. ${ }^{7}$

The risk of perioperative stroke was calculated by the Multicenter Perioperative Stroke Index (McSPI). ${ }^{12}$ The McSPI has been validated from a population of 2107 patients by the use of the bootstrap technique, a valuable method for validating predictive scales. The predicted risks of 30-day mortality, prolonged hospital stay, and perioperative stroke for the 27 patients are listed in Table III.

Multivessel coronary artery disease was defined as greater than $70 \%$ luminal narrowing in the distribution of more than 1 major coronary artery (eg, left anterior descending [LAD], right coronary artery, or circumflex. The goal of revascularization was not to obtain necessarily a "complete" revascularization, but rather a "functionally adequate" one. ${ }^{13}$ Functionally adequate revascularization was defined as revascularization of all stenoses of more than $70 \%$ in vessels with a diameter greater than $1.5 \mathrm{~mm}$ that served viable myocardium. Vessels serving infarcted ventricular territory, as demonstrated by either akinesis on the ventriculogram or fixed perfusion defects on thallium myocardial scintigraphy, were not considered functionally important. For stenoses in the intermediate range of severity (40\%-60\% luminal narrowing) ${ }^{14}$ revascularization was undertaken only if stress thallium ${ }^{15}$ or coronary flow reserve studies ${ }^{16}$ showed evidence of flow limitation.

Surgical technique. MICABG was performed through a 3inch minithoracotomy in the fourth or fifth intercostal space under direct vision of the surgeon, without removal of any costal cartilage or rib. Anesthesia was induced with propofol $(2-3 \mathrm{mg} / \mathrm{kg}$ ) and maintained with modest doses of fentanyl $(15-25 \mu \mathrm{g} / \mathrm{kg})$ and rocuronium $(0.4 \mathrm{mg} / \mathrm{kg})$. Intravenous infusion of diltiazem $(3-5 \mathrm{mg} / \mathrm{h})$, as an ischemic preconditioning agent, was used in all patients. A left-sided double-lumen endotracheal tube was used in all cases to facilitate left inter- 
Table IV. Revascularization strategy

\begin{tabular}{lc}
\hline Isolated MICABG & 20 patients $(74 \%)$ \\
Integrated MICABG/PTCA & 7 patients $(26 \%)$ \\
Same day & 5 patients $(5 / 7,71 \%)^{*}$ \\
POD 1 or 2 & 2 patients \\
Stent & 4 patients \\
PTCA only & 3 patients \\
Site & \\
LMCA & 1 patient \\
Circumflex & 4 patients \\
Diagonal & 1 patient \\
RCA & 1 patient \\
MICABG LITA-LAD & 27 patients \\
Anastomosis time & $14 \pm 2.3$ min \\
Operation time (skin-to-skin) & $122.6 \pm 28$ min \\
Extubation in OR & 18 patients $(67 \%)$ \\
\hline
\end{tabular}

$M I C A B G$, Minimally invasive coronary artery bypass; $P T C A$, percutaneous transluminal coronary angioplasty; $P O D$, postoperative day; $L M C A$, left main coronary artery; $R C A$, right coronary artery; LITA, left internal thoracic artery; $L A D$, left anterior descending coronary artery; $O R$, operating room.

*If left main coronary stenosis, MICABG was always performed first.

nal thoracic artery (LITA) harvest circumferentially as a pedicle for its entire length from the subclavian artery takeoff to the bifurcation (average length of LITA pedicle $=15 \mathrm{~cm}$ ). A dedicated LITA retractor (CardioThoracic Systems Inc, Cupertino, Calif) was successfully used and provided excellent exposure of the entire bed of the LITA. The heparin dose used was $100 \mathrm{IU} / \mathrm{kg}$. After division of the distal LITA, a 1/4force atraumatic bulldog vascular occluder (Applied Medical, Laguna Hills, Calif) was used to interrupt LITA flow. The LITA-LAD anastomosis was performed with a mechanical stabilizer (CardioThoracic Systems) without harmful pharmacologic manipulation of the heart rate ${ }^{17}$; the average heart rate during the anastomosis was 72 beats/min. The LITALAD anastomosis was performed with 2 separate $8-0$ polypropylene sutures at the heel and toe (double-parachute technique) with a $6.5-\mathrm{mm}$ needle with the help of a carbon dioxide blower used very sparingly and set at a flow not higher than $5 \mathrm{~L} / \mathrm{min}$ to avoid damage to the coronary endothelium. Before final tying of the suture, the anastomosis was probed with a nonocclusive 1-mm Parsonnet probe in 3 directions: proximal LAD, distal LAD, and proximal LITA; furthermore, the LITA was flushed through the open suture line before final tying of the knot to eliminate the potential for thrombus formation at the site of application of the vascular occluder. On completion of the anastomosis, the flow pattern of the LITA was immediately analyzed with a customized ultrasound transit-time flowmeter (Transonic Systems Inc, Ithaca, NY) as previously described by us. ${ }^{18}$ Extubation was attempted in all cases in the operating room. Postoperative pain control was achieved by a preoperatively placed epidural catheter or by intercostal nerve block when an epidural catheter was contraindicated (eg, with intravenous heparin infusion). In patients with normal renal function, an age-adjusted bolus of ketorolac was administered intravenously before reversal of neuromuscular blockade. Compared with more routine
MICABG, when dealing with high-risk patients we are especially careful to avoid even brief episodes of hypotension; thus a mean arterial pressure greater than $80 \mathrm{~mm} \mathrm{Hg}$ is actively maintained by means of phenylephrine and volume infusions. Furthermore, arterial oxygen saturation is maintained higher than $95 \%$ and manipulation of heart rate is avoided. LITALAD anastomotic patency was confirmed angiographically in all 27 patients within 48 hours of MICABG. Our MICABG follow-up protocol included exercise or pharmacologic stress thallium myocardial scintigraphy, Doppler echocardiography of LITA flow, ${ }^{19}$ and physical examination at 1 month.

Statistical analysis. Data were expressed as mean \pm standard deviation. Comparison between predicted and observed length of stay in the hospital was performed by means of the sign test. For comparison of observed and predicted number of events, the $P$ value was computed by means of a permutation test, that is, the probability of observing no events in the study population given each patient's predicted probability of the event. We note here and in the discussion that the predicted probabilities of events have an inherent variability that is relatively high. Although the comparisons remained significant under robustness calculations using the lower 95\% confidence limit for each patient's estimate as the predicted value, the $P$ values reported are nevertheless approximate.

The protocol for MICABG and integrated coronary revascularization was approved by the Institutional Review Board of the University of Pittsburgh, and informed consent was obtained from all patients.

\section{Results}

Characteristics of the operations performed are listed in Table IV. In 7 patients $(7 / 25,28 \%)$, MICABG was integrated with percutaneous coronary revascularization of non-LAD coronary arteries in the cardiac catheterization laboratory. ${ }^{20,21}$ Details of MICABG and integrated coronary revascularization strategy are listed in Table IV. All patients in whom a stent was used in conjunction with integrated coronary revascularization received aspirin and ticlopidine ( $250 \mathrm{mg}$ by mouth twice a day) for 1 month after revascularization. All patients survived MICABG (30-day mortality $=0)$ : at a mean follow-up of $10.8 \pm 4.1$ months, the survival is $96.3 \%$ (1 patient with acquired immunodeficiency syndrome died on postoperative day 40 of acute pancreatitis).

The predicted 30-day mortality for this cohort of patients according to the System $97^{11}$ was $25.6 \% \pm$ $11.3 \%(P<.01$ vs observed; Table III).

Three patients $(11 \%)$ had postoperative atrial fibrillation. One patient required reintubation on postoperative day 2 for bradycardia ( $\beta$-blocker overdose). One patient had temporary worsening of renal dysfunction (creatinine level rose from 2.0 to $3.3 \mathrm{mg} / \mathrm{dL}$ ) after integrated coronary revascularization with the use of contrast material. One patient was readmitted to the hospital on postoperative day 15 for upper gastrointestinal 


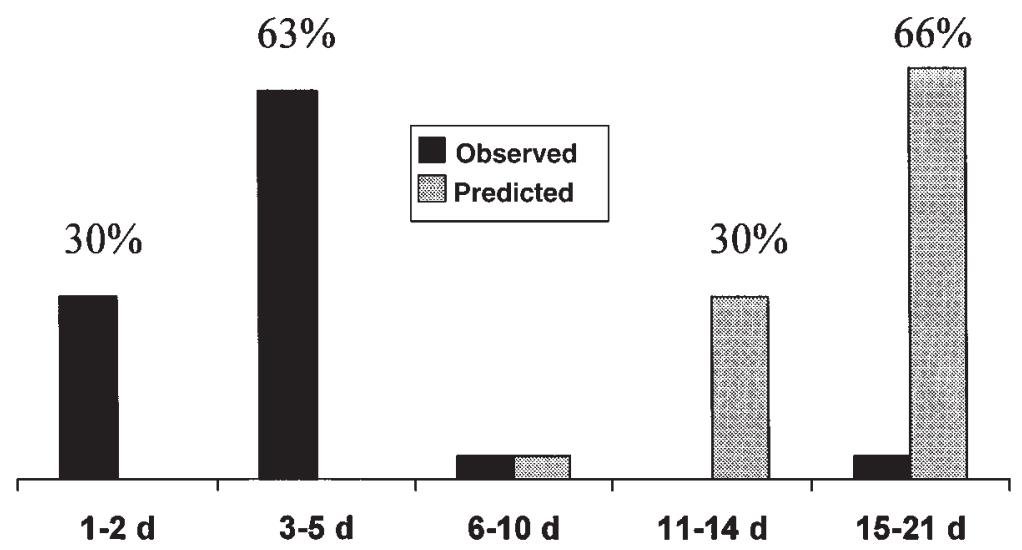

Fig 1. Length of stay, observed versus predicted.

tract bleeding that was treated conservatively. Another patient, in whom a $95 \%$ stenosis of the proximal subclavian artery was detected before MICABG, underwent successful stent placement with reduction of the stenosis from $95 \%$ to $5 \%$ and subsequently underwent successful MICABG.

In another patient with severe peripheral vascular disease, a total occlusion of the proximal subclavian artery was detected after MICABG at the time of the control LITA angiogram; interestingly, this patient did not have any blood pressure gradient between the right and left arm before the operation, most likely because of compensatory circulation from a large patent vertebral artery. This patient underwent successful carotid-subclavian bypass on postoperative day 2 after MICABG to prevent a future steal phenomenon and was discharged home on postoperative day 4 .

LITA-LAD patency was confirmed in all 27 patients $(27 / 27,100 \%)$ by contrast angiography. Patency was also confirmed by intraoperative transit-time flowmetry and postoperative Doppler flow study. The postprocedure hospital stay was 3.9 \pm 3.5 days (range 2-16 days), compared with a predicted hospital stay based on the Parsonnet score of $15.3 \pm 3$ days ( $P<.01$ vs predicted) (Table III and Fig 1). No patient had a postoperative stroke or major neurologic event after the procedure (stroke incidence $=0 \%$ ), compared with a predicted risk of stroke according to the McSPI of $22.3 \% \pm$ $11.7 \%$ ( $P<.01$ vs predicted). At a mean follow-up of $10.8 \pm 4.1$ months, all 26 surviving patients are free of recurrent angina and myocardial infarction.

\section{Discussion}

The risk profile of patients being referred for surgical coronary revascularization has been steadily increasing in severity during this decade. ${ }^{2}$ Recent studies suggest that elderly patients with greater comorbidities and advanced cardiovascular disease benefit more from cardiac surgery than from medical therapy, ${ }^{22,23}$ yet they paradoxically have greater morbidity and mortality after cardiac surgery. ${ }^{24,25}$ Despite the 30 years that have elapsed since the first CABG was performed by Favaloro in 1967, and myriad subsequent refinements in technique, major complications continue to be associated with $\mathrm{CABG}$, resulting in prolonged hospitalizations and resource use. Because the majority of complications after $\mathrm{CABG}$ are related to the use of $\mathrm{CPB}$, a revascularization strategy that eliminates $\mathrm{CPB}$ would seem a logical solution, especially in high-risk patients, provided that equivalent effectiveness can be demonstrated. MICABG provides such an alternative, although it is limited in its scope to the anterolateral left ventricular coronary distribution (LAD, diagonal, ramus intermedius). ${ }^{26}$ To provide a "functionally adequate" revascularization ${ }^{13}$ for patients with multivessel coronary artery disease, we have previously described an approach that we called "integrated coronary revascularization," which combines MICABG LITA-LAD with angioplasty of non-LAD coronary lesions. ${ }^{20}$

We hypothesized that a coronary revascularization strategy that eliminates $\mathrm{CPB}$, such as isolated or integrated MICABG, would yield superior results in highrisk patients compared with those of standard CABG. We used the Parsonnet risk score ${ }^{9}$ to screen a consecutive group of patients who received MICABG at our institution during a 12-month period; 27 patients with a Parsonnet score greater than $20 \%$ were identified. Ideally, a randomized study design would be best to assess the relative merits of standard $\mathrm{CABG}$ and MICABG in this "extremely high-risk"

Unfortunately, $74 \%$ of patients in our group had been turned down as candidates for standard CABG by 1 or more surgeons because of anticipated prohibitive risk; the remaining 7 patients were never referred for con- 
ventional $\mathrm{CABG}$ by the cardiologist. Therefore we decided to test the observed outcome after MICABG against the best risk assessment models available for these patients. The outcomes assessed were 30-day mortality, prolonged hospital stay (and resource use), and stroke.

We observed no mortality, no stroke, and a postprocedural hospital stay of 3.9 days in our 27 extremely highrisk patients, figures that compare very favorably with the predicted outcomes had standard CABG been used. The short-term (10.8 months) follow-up results are encouraging, with a $96.3 \%$ survival and a $100 \%$ freedom from coronary events in all surviving patients. Length of stay in the hospital appears to be prolonged if major problems occur after the operation with any organ system. Multiple studies have used length of stay as a measure of resource use $^{27}$; our reduced length of hospital stay is most likely due to the absence of major organ complications after MICABG. Stroke after CABG is a devastating complication. ${ }^{28}$ The reported overall incidence of stroke for standard CABG ranges widely from $0.8 \%$ to $3.2 \%$ in retrospective studies and from $1.5 \%$ to $5.2 \%$ in prospective studies. ${ }^{29}$ The mortality rate from stroke in patients who have had CABG ranges from $0 \%$ to $38 \%$. In a recent study, stroke dramatically increased the mean hospital stay from 8.7 days to 25.2 days. The mortality rate for patients having a stroke was $19.2 \%$ compared with $4.2 \%$ of the overall study population. ${ }^{29}$ Arom and associates ${ }^{30}$ reported a $12 \%$ incidence after MICABG; they relied on pharmacologic bradycardia using esmolol and adenosine boluses to minimize the motion of the beating heart. It is possible that the drastic reduction in cardiac output during pharmacologic bradycardia ${ }^{17}$ can result in hypoperfusion to the brain and ischemic stroke. The absence of stroke in our very high-risk patients undergoing MICABG, even when the predicted incidence by McSPI was $22 \%$, is most likely due to the careful avoidance of pharmacologic bradycardia, maintenance of high mean arterial pressure $(>80 \mathrm{~mm} \mathrm{Hg}$ ) throughout the operation, and optimal arterial oxygen saturation.

A limitation of the formal comparisons of observedto-expected rates of events and hospital stay is that relatively few of the patients in the CABG cohorts used to calculate rate estimates were high risk. As a result, the variability of the estimated outcomes for our small group of patients having MICABG is quite high. The highly significant $P$ values in this report must therefore be regarded as approximate, because they do not rigorously take this variability into account. Our primary goal in this report, however, is to point out the extremely low event rates and short hospital stay associated with MICABG, rather than to carry out a formal statistical comparison or quantify the expected reduction of risk.
In conclusion, MICABG, isolated or integrated with percutaneous intervention, improves outcome in extremely high-risk patients requiring coronary revascularization and does not correlate with the expected outcome based on risk assessment models geared for standard CABG. Despite the small size of our patient population, we suggest that MICABG has the potential to expand the benefit of surgical coronary revascularization to patients with otherwise inoperable heart disease. Long-term follow-up of these clinical results is therefore warranted.

\section{REFERENCES}

1. Kutryk MJB, Serruys PW. Stenting. In: Topol EJ, editor. Textbook of cardiovascular medicine. Philadelphia: LippincottRaven; 1998. p. 2033-64.

2. Williams TE, Fanning WJ, Link L, Benton WC, Kakos GS, Miller RL, et al. Can we afford to do cardiac operations in 1996 ? A risk-reward curve for cardiac surgery. Ann Thorac Surg 1994;58:815-21.

3. Elefteriades JA. Mini-CABG: A step forward or backward? J Cardiothorac Vasc Anesth 1997;11:661-8.

4. Tseng EE, Lee CA, Salazar JD, Doty JR, Greene PS, Goldsborough $\mathrm{M}$, et al. Mean arterial pressures on cardiopulmonary bypass correlate with neurologic outcome in high strokerisk patients [abstract]. Circulation 1997;96(Suppl):I282.

5. Mora CT, Murkin JM. The central nervous system: responses to cardiopulmonary bypass. In: Mora CT, editor. Cardiopulmonary bypass: principles and techniques of extracorporeal circulation. New York: Springer Verlag; 1995. p. 114-46.

6. Calafiore AM, Di Giammarco G, Teodori G, Bosco G, D'Annunzio E, Barsotti A, et al. Left anterior descending coronary artery grafting via left anterior small thoracotomy without cardiopulmonary bypass. Ann Thorac Surg 1996;61:1658-65.

7. Zenati M, Domit TM, Saul M, Gorcsan J, Katz WE, Hudson M, et al. Resource utilization for minimally invasive direct and standard coronary artery bypass. Ann Thorac Surg 1997;63:S84-7.

8. Doty IR, Fonger JD, Nicholson CF, Sussman MS, Salomon NW. Cost analysis of current therapies for limited coronary revascularization. Circulation 1997;96(Suppl):II16-20.

9. Parsonnet V, Dean D, Bernstein AD. A method of uniform stratification of risk for evaluating the results of surgery in acquired adult heart disease. Circulation 1989;79(Suppl):I3-12 .

10. Katz NM, Chase GA. Risks of cardiac operations for elderly patients: reduction of the age factor. Ann Thorac Surg 1997; 63:1309-14

11. Parsonnet V, Bernstein AD. Development of practical methods for estimating preoperative risk of mortality in cardiac surgery: the New Jersey experience [abstract]. Circulation 1996;94:2971.

12. Newman MF, Wolman R, Kanchuger M, et al. Multicenter preoperative stroke risk index for patients undergoing coronary artery bypass graft surgery. Circulation 1996;94(Suppl):II74-80.

13. Faxon DP, Ghalilli K, Jacobs AK, Ruocco NA, Christellis EM, Kellett MA, et al. The degree of revascularization and outcome after multivessel coronary angioplasty. Am Heart J 1993;123; 854-9.

14. Herrman JPR, Azar A, Umans VAWM, Boersma E, Es GA, Serruys PW. Inter- and intra-observer variability in the qualitative categorization of coronary angiograms. Int J Card Imaging 1996; 12:21-30. 
15. Brown KA, Rowen M. Prognostic value of a normal exercise myocardial perfusion imaging study in patients with angiographically significant coronary artery disease. Am J Cardiol 1993;71: 865-7.

16. Kern MJ, De Brunye B, Pijls NHJ. From research to clinical practice: current role of intracoronary physiologically based decision making in the cardiac catheterization laboratory. J Am Coll Cardiol 1997;30:613-20.

17. Jurmann MJ, Menon A, Guggenberger H, Haeberle L, Ziemer G. Pharmacologic versus mechanical stabilization of the heart during minimally invasive coronary artery bypass: effects on left ventricular geometry and hemodynamics [abstract]. Circulation 1997;96(Suppl):I680.

18. Mandarino WA, Gorcsan J, Katz WE, Cohen HA, Griffith BP, Zenati M. Intraoperative analysis of left internal mammary artery graft flow patterns following minimally invasive coronary bypass [abstract]. J Am Coll Cardiol 1998;31:464A-5A.

19. Katz WE, Zenati M, Mandarino WA, Gorcsan J. Noninvasive assessment of left internal mammary artery graft patency and flow reserve after minimally invasive coronary bypass using Doppler echocardiography [abstract]. J Am Coll Cardiol 1998; 31:386A

20. Cohen HA, Zenati M, Griffith BP, Smith AJC, Lee JS, Chough S, et al. Integrated coronary revascularization-minimally invasive coronary bypass combined with angioplasty: initial experience in 25 patients [abstract]. J Am Coll Cardiol 1998;31:70A.

21. Zenati M, Cohen HA, Chough SH, Smith CA, Lee JS, Feldman $\mathrm{M}$, et al. Integrated coronary revascularization for left main coronary disease: an alternative approach with minimally invasive bypass surgery and TCT [abstract]. Am J Cardiol 1997;80: (Suppl):I85.
22. Califf RM, Harrell FE, Lee KL, Rankin JS, Mark DB, Hlatly MA, et al. Changing efficacy of coronary revascularization: implications for patient selection. Circulation 1988;78(Suppl): I185-91.

23. Gersh B, Kornmal R, Schaff H, Frye RL, Ryan TJ, Mock MB, et al. Comparison of coronary artery bypass surgery and medical therapy in patients 65 years of age or older. N Engl J Med 1985; $313: 217-24$

24. Jones EL, Weintraub WS, Craver J, Guyton R, Cohen C. Coronary bypass surgery: Is the operation different today? J Thorac Cardiovasc Surg 1991;101:108-15.

25. Mohan R, Amsel BJ, Walter PJ. Coronary artery bypass grafting in the elderly: a review of studies on patients older than 64,69 or 74 years. Cardiology 1992;80:215-25.

26. Holubkov R, Zenati M, Akin J, Courcoulas AP. Profiles and outcomes of patients undergoing minimally invasive direct coronary artery bypass (MIDCAB): the CTS Registry [abstract]. Circulation 1997;96(Suppl):682.

27. Smits HL, Fetter RB, McMahon LF Jr. Variation in resource use within diagnosis related groups: the severity issue. Health Care Fin Rev 1984;6;71-8.

28. Roach GW, Kanchuger M, Mora Mangano C, Newman M, Nussmeier N, Wolman R, et al. Adverse cerebral outcomes after coronary bypass surgery. N Engl J Med 1996;335:1857-63.

29. McKhann GM, Goldsborough MA, Borowicz LM, Mellits ED, Brookmeyer R, Quaskey SA, et al. Predictors of stroke risk in coronary artery bypass patients. Ann Thorac Surg 1997,63:516-21.

30. Arom KV, Emery RW, Nicoloff DM, Flavin TF, Emery AM. Minimally invasive direct coronary artery bypass grafting: experimental and clinical experience. Ann Thorac Surg 1997;63:54852. 